\title{
Barry Karger: Septuagenarian!
}

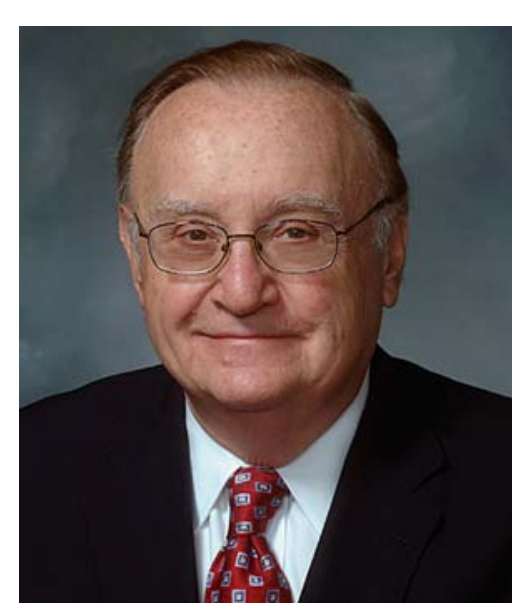

Time passes by so fast that it is hard to believe that it is 10 years ago that I wrote an Editorial to mark Barry Karger's sixtieth birthday. ${ }^{1}$ It is not necessary to repeat his scientific achievements starting with gas chromatography, and already in 1968 with liquid chromatography, to capillary electrophoresis, and coupling these techniques to mass spectrometry and NMR. He is still actively present at international meetings delivering outstanding lectures with new and interest- ing results in the field of separation science with a special focus on bioscience.

$\mathrm{He}$ has the ability to attract young scientists as postdocs as well as renowned researchers as visiting professors to the Northeastern University and the Barnett Institute. His approach of mixing young scientist from all over the world and of different backgrounds - chromatography, electrophoresis, mass spectrometry and NMR on the instrumental side with biochemists with the need for analysis on the other-has created an extremely successful research community. He has the ability to persuade various scientific organizations and committees to donate sufficient money for his research.

In his laboratory at the beginning of his career he attracted postdocs from Germany (I started 1969 as his first postdoc), England, France, and Argentina. With the raising of the Iron Curtain Hungarians, (I remember a visit to his laboratory when the language of everyone was Hungarian) Czechs and Russians followed, and are now succeeded by Chinese and Indians. Many of his former research associates became well-known scientists in their home countries, just to name a few, like W. Lindner (Vienna), P. Schoenmakers (Amsterdam), N. Tanaka (Kyoto), and myself at Saarbrücken.

At the age of seventy Barry Karger is still very active and even starting new projects in the search for applications of separation science in clinical diagnosis and opening new approaches in the search for biopharmaceuticals.

In conclusion, as I did 10 years ago, I wish him on behalf of his friends and the Chromatographia team personal prosperity, time to spend with his family and his grandsons, the best of health and still many years of enthusiastic and stimulating research in the field of separation sciences.

Ad multos annos.

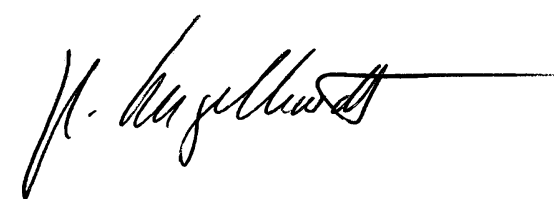

Heinz Engelhardt

Wendelstein, April 2009 